\title{
Biliary Migration, Colonization, and Pathogenesis of O. viverrini Co-Infected with CagA+ Helicobacter pylori
}

\author{
Watcharapol Suyapoh ${ }^{1,2}$, Janina E. E. Tirnitz-Parker ${ }^{3}$, Sirikachorn Tangkawattana ${ }^{2,4} \mathbb{D}^{\text {, Sutas Suttiprapa }}{ }^{2,5}$ \\ and Banchob Sripa $2,6, *$ (D)
}

1 Biomedical Sciences Program, Graduate School, Khon Kaen University, Khon Kaen 40002, Thailand; watcharapol_su@hotmail.com

2 WHO Collaborating Centre for Research and Control of Opisthorchiasis (Southeast Asian Liver Fluke Disease), Faculty of Medicine, Khon Kaen University, Khon Kaen 40002, Thailand; sirikach@kku.ac.th (S.T.); sutasu@kku.ac.th (S.S.)

3 Liver Disease and Regeneration Group, Curtin Medical School, Curtin Health Innovation Research Institute, Curtin University, Perth 6102, Australia; n.tirnitz-parker@curtin.edu.au

4 Faculty of Veterinary Medicine, Khon Kaen University, Khon Kaen 40002, Thailand

5 Tropical Medicine Graduate Program, Faculty of Medicine, Khon Kaen University, Khon Kaen 40002, Thailand

6 Tropical Disease Research Center, Department of Pathology, Faculty of Medicine, Khon Kaen University, Khon Kaen 40002, Thailand

* Correspondence: banchob@kku.ac.th; Tel.: +66-62-6080860; Fax: +66-43-363319

Citation: Suyapoh, W.; Tirnitz-Parker, J.E.E.; Tangkawattana, S.; Suttiprapa, S.; Sripa, B. Biliary Migration, Colonization, and Pathogenesis of $O$. viverrini Co-Infected with CagA+ Helicobacter pylori. Pathogens 2021, 10, 1089. https://doi.org/10.3390/ pathogens 10091089

Academic Editors: Jose

Muñoz Gutiérrez and

Andrew Taylor-Robinson

Received: 19 June 2021

Accepted: 23 August 2021

Published: 26 August 2021

Publisher's Note: MDPI stays neutral with regard to jurisdictional claims in published maps and institutional affiliations.

Copyright: (c) 2021 by the authors. Licensee MDPI, Basel, Switzerland. This article is an open access article distributed under the terms and conditions of the Creative Commons Attribution (CC BY) license (https:// creativecommons.org/licenses/by/ $4.0 /)$.

\begin{abstract}
Co-infection with the cagA strain of Helicobacter pylori exacerbates the pathology of human liver fluke Opisthorchis viverrini (OV) infection leading to cholangiocarcinoma. However, underlying mechanisms remain unclear. We report a significant increase in cagA-positive and cagA-negative H. pylori in the stomach, blood, bile, and in the OV worms of co-infected Syrian golden hamsters at one hour, three hours, and one month, post-infection, compared to hamsters infected with either OV or H. pylori alone. Except in the worms, H. pylori numbers declined at three months post-infection, particularly in the bile fluid of co-infected animals. Both strains of H. pylori were immunohistochemically detected in the tegument of the worm, as well as in the bile duct epithelium when co-infected with O. viverrine, but not in $H$. pylori infection alone. Interestingly, only the cagA-positive strain was detected in the gut of the worm. Co-infection between cagA-positive H. pylori and O. viverrini resulted in a more severe biliary pathology and decreased E-cadherin expression in vivo and in vitro than those of the cagA-negative strain. These data suggest that $O$. viverrini acts as a carrier of cagA-positive $H$. pylori and co-migrates to the bile ducts, whereas $O$. viverrini facilitates $H$. pylori colonization and enhances the biliary pathogenesis and carcinogenesis.
\end{abstract}

Keywords: Opisthorchis viverrini; Helicobacter pylori; co-infection; migration; colonization; pathogenesis

\section{Introduction}

Chronic infection of humans with the carcinogenic liver fluke, Opisthorchis viverrini, is a major public health problem in the Lower Mekong region, including Thailand, Lao People's Democratic Republic, Cambodia, and Southern Vietnam. Approximately ten million people in these areas are infected with this particular liver fluke [1]. In Thailand, the highest prevalence is reported in the north-eastern part, where about six million people are infected $[2,3]$. Infection occurs by consuming raw or undercooked freshwater fish containing the infective stage (metacercaria) of the parasite. After ingestion by the host, the metacercaria excyst in the duodenum. The worm then enters the bile duct via the ampulla of Vater before migrating to the intrahepatic bile ducts, where it develops into an adult worm. Chronic bile duct infection causes several hepatobiliary abnormalities, including biliary periductal fibrosis and the lethal bile duct cancer cholangiocarcinoma (CCA). Thus, O. viverrini was classified by the International Agency for Research on Cancer (IARC) as a Group 1 biological carcinogen to humans [4]. Interestingly, recent studies have shown that 
O. viverrini co-infected with Helicobacter pylori may exacerbate hepatobiliary diseases and orchestrate opisthorchiasis-mediated CCA [5].

H. pylori, a rod-shaped bacterium in the genera Proteobacteria, is classified as a Group 1 carcinogen that has been known to cause gastric cancer [4]. H. pylori can be divided into two major subpopulations based on the presence or absence of the cagA gene, the key virulence factors involving in pathogenesis of the disease, that encodes the CagA protein: $\operatorname{cag} A$-positive and $\operatorname{cag} A$-negative strains [4]. Proteobacteria are a key population of microbiotas detected in worms, bile samples, and the feces of hamsters infected with O. viverrini [6]. A subsequent study has revealed that the liver fluke is a reservoir host of H. pylori [7]. Furthermore, co-infection of O. viverrini with $H$. pylori enhanced hepatobiliary inflammation and periductal fibrosis in a hamster model [8]. In humans from O. viverriniendemic areas, the $H$. pylori infection rate is higher in $O$. viverrini-infected than uninfected residents [9]. Of note, $H$. pylori bacterial loads are positively correlated with the intensity of $O$. viverrini infection. Interestingly, biliary periductal fibrosis, the major pathologic characteristic of chronic opisthorchiasis, is associated with cagA-positive H. pylori [9]. Boonyanugomol et al. [10] reported a significantly higher rate of $H$. pylori detection in bile samples of CCA patients (66.7\%) compared to non-cancer controls $(25.0 \%)$. Moreover, cagA-positive $H$. pylori had a significantly stronger association with CCA than cholelithiasis or non-cancer controls in the study. These data suggest that cagA-positive H. pylori is involved in the pathogenesis of hepatobiliary abnormalities and CCA.

However, despite a strong link between the two carcinogenic pathogens mentioned above, underlying mechanisms remain elusive. Therefore, this study in a hamster model aimed to investigate the relationship between $O$. viverrini and $H$. pylori, with particular focus on how $H$. pylori migrates, colonizes, and induces pathologies of the bile ducts in co-infection with $O$. viverrini.

\section{Materials and Methods}

\subsection{Metacercaria Preparation}

O. viverrini infective stage metacercariae were obtained from naturally infected freshwater cyprinoid fish in an endemic area of Thailand. Five $\mathrm{kg}$ of fresh fish were minced and digested in synthetic stomach juice containing $0.15 \%$ hydrochloric acid $(\mathrm{HCl})$ and $0.25 \%$ pepsin and incubated in a water bath at $37^{\circ} \mathrm{C}$ for $1 \mathrm{~h}$. After digestion, the suspension was filtered in a series of copper sieves with different pore sizes to remove solid particles and sedimented in normal saline, as reported previously [11]. O. viverrini metacercariae were identified under a dissecting microscope as previously described [12]. Fifty metacercariae were fed to the hamsters via intragastric intubation.

\subsection{Bacterial Preparation}

Two bacterial strains, cagA-positive and cagA-negative $H$. pylori tagged with green fluorescent protein mutant 2 gene ( $g f p$ mut 2 ) were kindly provided by Prof. R. Haas, Max von Pettenkofer Institut für Hygiene und Medizinische Mikrobiologie [13]. Both strains were grown on GC selective agar plates, supplemented with $6 \mathrm{mg} / \mathrm{L}$ chloramphenicol (chloramphenicol supplement, Oxoid Limited, Hampshire, England), 10mL/L vitox (Vitox supplement, Oxoid Limited, Hampshire, England), Dent (H. pylori selective supplement, Oxoid Limited, Hampshire, England), and horse serum (5\%). The plates were incubated for $4-5$ days at $37{ }^{\circ} \mathrm{C}$ in $6-12 \% \mathrm{O}_{2}$ and $5-8 \% \mathrm{CO}_{2}$ microaerobic atmosphere adjusted by 1 sachet/2.5L jar of gas generator (AnaeroPack-MicroAero Gas Generator, Mitsubishi Gas Chemical Co. Ltd., Tokyo, Japan) [14]. After sufficient bacterial growth, H. pylori colonies were suspended in Brucella broth, mixed, and washed several times, and adjusted to $1.7 \times 10^{8}$ colony forming units (CFUs) $/ \mathrm{mL}$ [15]. Hamsters were given $1 \mathrm{~mL}$ of the bacterial solution orally, using a stomach tube $24 \mathrm{~h}$ after fasting. 


\subsection{Experimental Design}

Six-week-old male Syrian hamsters $(n=50)$ were assigned to 5 groups of 10 animals each (Figure 1a). Group I (OV): O. viverrini infection, Group II (OV/HP+): O. viverrini + cagA-positive H. pylori infection, Group III (OV/HP-): O. viverrini + cagA-negative H. pylori infection, Group IV (HP+): cagA-positive H. pylori infection, Group V (HP-): cagA-negative $H$. pylori infection. All animals were kept under controlled temperature and day/night cycle conditions and provided with food and water ad libitum. This animal study was approved by the Animal Ethics Committee of Khon Kaen University (AEKKU \#41/2561).

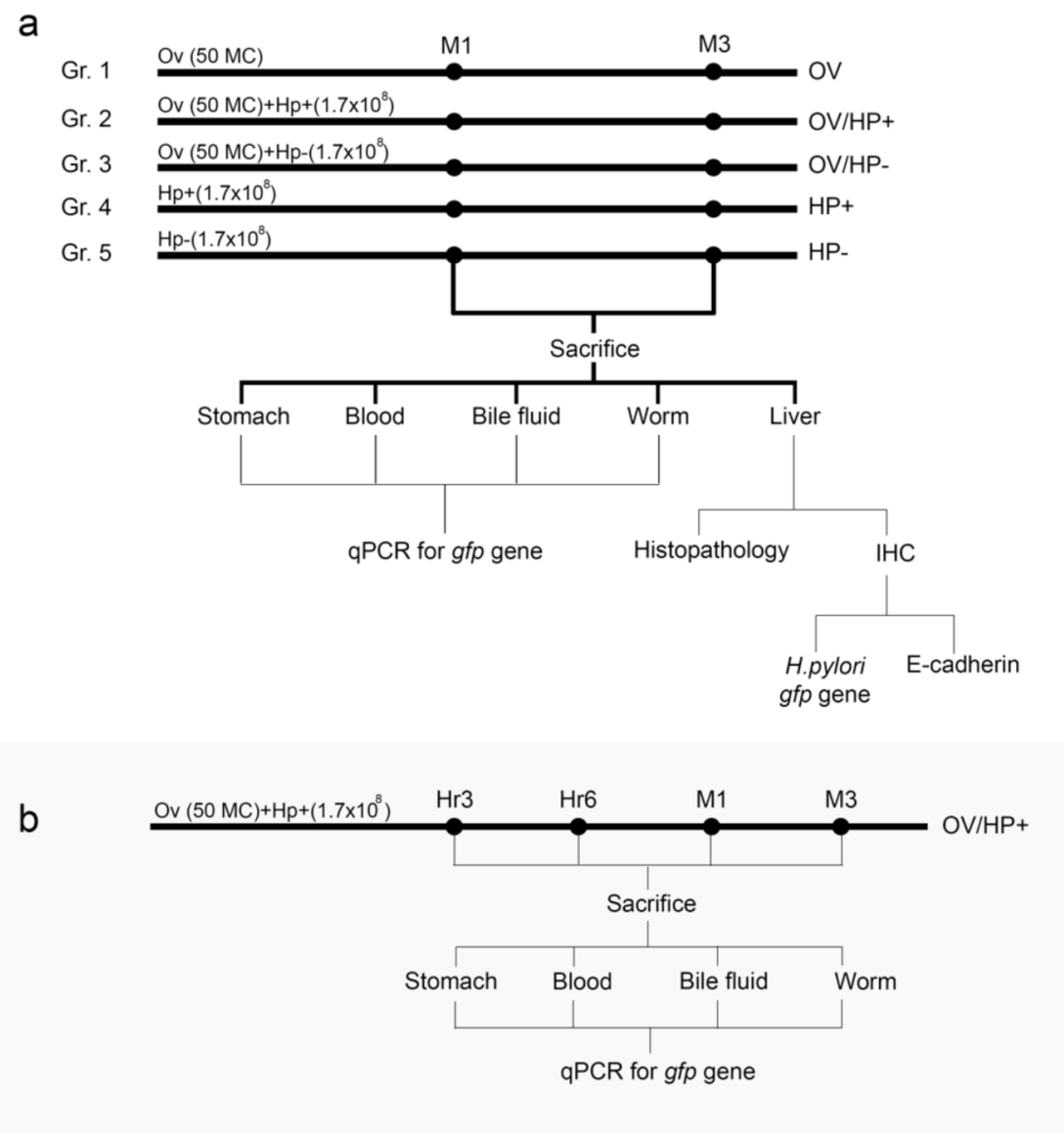

Figure 1. Experimental design. (a). Long-term study using 5 different infection groups of hamsters sacrificed, and sample collected at 1 month-6 months. (b). Short-term study using O. viverrini and cagA-positive $H$. pylori co-infected and sample collected at 1 and $3 \mathrm{~h}, 1$ month, and 3 months. $\mathrm{OV}=\mathrm{O}$. viverrini infection alone, $\mathrm{OV} / \mathrm{HP}-=\mathrm{O}$. viverrini infection + cagA-negative $H$. pylori, $\mathrm{OV} / \mathrm{HP}+=\mathrm{O}$. viverrini infection + cagA-positive $H$. pylori, $\mathrm{HP}+=$ cagA-positive $H$. pylori infection alone, HP- = cagA-negative $H$. pylori infection alone.

Five hamsters per group were euthanized by isoflurane inhalation at 1 and 3 months after infection and the liver, stomach, bile fluid, blood, and worms were collected. The liver was fixed in $10 \%$ neutral buffered formalin and processed by routine paraffin histological technique. The paraffin sections were then used for immunofluorescence and immunohistochemistry studies.

Additional experiments for a short-term study were O. viverrini and cagA-positive H. pylori co-migration assigned at 1 and $3 \mathrm{~h}$ after infection (Figure $1 \mathrm{~b}$ ). Five hamsters per time period were euthanized and samples were collected as outlined above. 


\subsection{DNA Extraction}

Whole blood ( $250 \mu \mathrm{L}$ per animal) was lysed repeatedly in red blood cell lysis buffer (0.32 M sucrose, $10 \mathrm{mM}$ Tris HCL, $5 \mathrm{mM} \mathrm{MgCl} 2,0.75 \%$ Triton-X-100) until white pellet was obtained [16]. Whole bile fluid was centrifuged at $5000 \times \mathrm{g}$ for $5 \mathrm{~min}$ at $4{ }^{\circ} \mathrm{C}$. Blood and bile pellets, $1 \mathrm{~g}$ of stomach tissue and whole worm samples were used for DNA extraction using the standard phenol-chloroform method [17]. Briefly, the samples were incubated with a DNA extraction buffer consisting of $20 \mathrm{mM}$ Tris-HCl, $1 \mathrm{mM}$ EDTA, $10 \mathrm{mM} \mathrm{NaCl}$, $10 \%$ sodium dodecyl sulfate, adjusted to $\mathrm{pH} 8$. The stomach and worm samples were homogenized with a tissue grinder and digested with proteinase $\mathrm{K}(10 \mathrm{mg} / \mathrm{mL}$ of proteinase $\mathrm{K}, 50 \mathrm{mM}$ Tris- $\mathrm{HCl}$, adjusted to $\mathrm{pH} 7.5$ ) at $55^{\circ} \mathrm{C}$ overnight. The DNA was then separated from the sample solutions by phenol and chloroform extraction and precipitated with ethanol. The DNA concentration was measured by using a NanoDrop®ND1000 UV-Vis Spectrophotometer (Thermo Fisher Scientific, Inc., Waltham, MA, USA) and adjusted to $50 \mathrm{ng} / \mu \mathrm{L}$.

\subsection{Real-Time Polymerase Chain Reaction ( $q P C R$ ) for gfp Gene Detection}

Recombinant plasmid, phel12 containing gfp was extracted using the Plasmid Extraction kit (GeneJET Plasmid Miniprep Kit, Thermo Fisher Scientific, Inc., Waltham, MA, USA) and used to prepare a qPCR standard curve. The DNA copy number was calculated as previously published [18] with a size of phel12 containing $g f p$ of $5116 \mathrm{bp}$. The plasmid solution was serially diluted 10 -fold, resulting in dilutions ranging from $1 \mathrm{ng} / \mu \mathrm{L}$ to $1 \mathrm{fg} / \mu \mathrm{L}$. Absolute quantification was performed by generating a standard curve for each $g f p$ and plotting the quantification cycle $(\mathrm{Cq})$ values against log [quantity] of a dilution series of known $g f p$ amounts.

The reaction mixture consisted of $10 \mu \mathrm{L}$ of $1 x$ Master Mix (FastStart Universal SYBR Green Master (Rox), Roche, Mannheim, Germany) containing FastStart Taq DNA polymerase, reaction buffer, nucleotides (dATP, dCTP, dGTP, and dTTP), SYBR Green I and a reference dye. A $g f p$ primer set, forward- TCCATGGCCAACACTTGTCA and reverseCATAACCTTCGGGCATGGCA in a volume of $0.6 \mu \mathrm{L}$ of $300 \mathrm{nM}$ were added to the reaction tube, with $6.8 \mu \mathrm{L}$ of sterile distilled water mixed with diethylpyrocarbonate (DEPC). The DNA sample was used at $2 \mu \mathrm{L}$ per reaction tube, making a final reaction volume of $20 \mu \mathrm{L}$. The PCR and melting curve conditions were set as $94{ }^{\circ} \mathrm{C} 30 \mathrm{~s}, 58{ }^{\circ} \mathrm{C} 30 \mathrm{~s}, 72{ }^{\circ} \mathrm{C} 45 \mathrm{~s}$ (50 cycles) and $95^{\circ} \mathrm{C} 30 \mathrm{~s}, 60^{\circ} \mathrm{C} 60 \mathrm{~s}, 95^{\circ} \mathrm{C} 15 \mathrm{~s}$. Expected gene product size was $112 \mathrm{bp}$.

\subsection{Immunofluorescence for Localization of H. pylori-GFP}

The liver tissue sections were deparaffinized and rehydrated prior to antigen retrieval by microwaving in $10 \mathrm{mM}$ citric acid, $\mathrm{pH} 6.0$ at $100 \mathrm{~W}$ for $5 \mathrm{~min}$ and $20 \mathrm{~W}$ for $15 \mathrm{~min}$. The sections were cooled down for 30 minutes, washed twice in phosphate-buffered saline (PBS), and endogenous peroxidases blocked with $3 \% \mathrm{H}_{2} \mathrm{O}_{2}$ in methanol. After blocking non-specific protein binding with $1 \%$ bovine serum albumin for $1 \mathrm{~h}$, the sections were incubated with mouse anti-GFP monoclonal antibody (Clone: GFP-20; G6539, Sigma-Aldrich, St. Louis, Missouri, MO, USA) at a dilution of 1:1000 in Tris-buffered saline (TBS) at $4{ }^{\circ} \mathrm{C}$ overnight. After washing, the sections were incubated with the secondary antibody (1:500 dilution), Alexa488-labeled goat-anti-mouse immunoglobulin (Thermo Fisher Scientific, Inc., Waltham, MA, USA) for $30 \mathrm{~min}$. After staining with Hoechst dye (1:2000 dilution in TBS) for $10 \mathrm{~min}$, the stained sections were mounted with $10 \%$ glycerol and observed under a fluorescence microscope (Olympus BX51, Olympus Corporation, Shinjuku-ku, Tokyo, Japan). The expression of GFP was confirmed by double-immunofluorescence staining with 1:50 in TBS rabbit anti-H. pylori polyclonal primary antibody (H. pylori strain $\mathrm{CH}-20426$; B0471, DakoCytomation, Glostrup, Denmark). Secondary antibodies used were goat anti-Mouse Alexa488 (1:500 dilution in TBS) and donkey anti-rabbit Alexa594 (1:500 dilution in TBS) (Thermo Fisher Scientific, Inc., Waltham, MA, USA) for $1 \mathrm{~h}$. 


\subsection{O. viverrini Excretory-Secretory Products Preparation}

Excretory-secretory products were obtained by culturing adult worms in vitro at $37^{\circ} \mathrm{C}$ in RPMI-1640 containing penicillin $(100 \mathrm{U} / \mathrm{mL})$, streptomycin $(100 \mu \mathrm{g} / \mathrm{mL})$, and protease inhibitors (0.1 mM phenylmethanesulfonyl fluoride (PMSF), $1 \mathrm{mM}$ leupeptin and $0.1 \mathrm{mM}$ $\mathrm{N}$-[N-(L-3-trans-carboxyoxiran-2-carbonyl)-L- leucine]-agmatine, E-64). Excretory-secretory products was collected every $12 \mathrm{~h}$ for 7 days from the medium of live worms. The medium was centrifuged to remove the eggs $\left(1000 \times g, 10 \mathrm{~min}\right.$ at $\left.4{ }^{\circ} \mathrm{C}\right)$. The clear supernatant was concentrated, and lipopolysaccharide (LPS) removed with Triton-X114 (Sigma-Aldrich, Missouri, MO, USA) as previous described [19]. After removal of residual Triton-X114 by Bio-Beads SM2 (Bio-Rad, California, CA, USA), the excretory-secretory products were filtered through a 0.2 micrometer membrane, protein measured, aliquoted and stored at $-80{ }^{\circ} \mathrm{C}$ for subsequent in vitro assays.

\subsection{H. pylori Adhesion Assay}

A normal biliary epithelial cell line $\mathrm{H} 69$ was seeded $\left(1 \times 10^{5}\right.$ cells/culture $)$ on $\mathrm{NaOH}-$ treated cover slides and cultured in enriched medium, which was a mixture of $45 \%$ Dulbecco's Modified Eagle's Medium: Nutrient Mixture F-12 (DMEM/F12, Gibco/ Thermo Fisher Scientific, Inc., Waltham, MA, USA), 45\% DMEM with high glucose (Gibco/ Thermo Fisher Scientific, Inc., Waltham, MA, USA) supplemented with $10 \%$ fetal bovine serum, penicillin $(100 \mathrm{U} / \mathrm{mL})$, streptomycin $(100 \mathrm{U} / \mathrm{mL})$, adenine $25 \mu \mathrm{g} / \mathrm{mL}$, insulin $5 \mu \mathrm{g} / \mathrm{mL}$, epinephrine $1 \mu \mathrm{g} / \mathrm{mL}$, hydrocortisone $0.62 \mu \mathrm{g} / \mathrm{mL}$, T3 $13.6 \mathrm{ng} / \mathrm{mL}$, epidermal growth factor $10 \mathrm{ng} / \mathrm{mL}$ and incubated at $37{ }^{\circ} \mathrm{C}$ in a $5 \% \mathrm{CO}_{2}$ humidified atmosphere for three days. The $\mathrm{H} 69$ cells were either treated with $H$. pylori at $80 \%$ confluency at $1: 1$ multiplicity of infection (MOI) or exposed to 1:1 MOI H. pylori under the presence of $20 \mu \mathrm{l} / \mathrm{mL}$ of excretory-secretory products for $24 \mathrm{~h}$. After incubation, the cells were washed with sterile PBS and fixed in 1:1 methanol: acetone for $5 \mathrm{~min}$. After washing, the cells were incubated with DAKO protein blocking solution (Dako Protein Block Serum Free: X0909, DakoCytomation, Glostrup, Denmark) for 20 min at room temperature and incubated with 1:500 dilution of mouse anti-H. pylori monoclonal antibody (Clone: BD1586; SC57780; Santacruz Biotechnology, Texas, Vt., USA) and rabbit anti-beta actin polyclonal primary antibody (1:250 dilution) (Ab8227; Abcam, Cambridge, United Kingdom) for $1 \mathrm{~h}$. The cells were then washed and incubated with 1:500 goat anti-mouse IgG-Alexa488 and 1:500 donkey anti-Rabbit IgG-Alexa594 (Thermo Fisher Scientific, Inc., Waltham, MA, USA) for $1 \mathrm{~h}$. After thorough washes with PBS, the cells were mounted with DAPI medium (ProLong Gold antifade reagent, Thermo Fisher Scientific, Inc., Waltham, MA, USA) for nuclear visualization and viewed under a fluorescence microscope (Olympus BX51, Olympus Coperation, Shinjuku-ku, Tokyo, Japan). The number of adherent $H$. pylori was manually evaluated at $40 \times$ magnification for 10 non-overlapping fields of view.

\subsection{Epithelial Transmigration Assay}

The epithelial transmigration of $H$. pylori was studied using the $\mathrm{H} 69$ cell line with the number of cells and slide preparation performed as described for the H. pylori adhesion assay. For the experimental design, the cell lines were assigned to two groups. In group 1, cagA-positive H. pylori was added to $80 \%$ confluent cell cultures at 1:1 MOI. For group 2, the $80 \%$ confluent cultures were exposed to 1:1 MOI cagA-positive $H$. pylori under the presence of $20 \mu \mathrm{g} / \mathrm{mL}$ of excretory-secretory products. Both groups were cultured for 3, 6 and $24 \mathrm{~h}$. After incubation, the cells were washed with sterile PBS and fixed in 1:1 methanol: acetone for $5 \mathrm{~min}$. The cells were then incubated with DAKO protein blocking solution (Dako Protein Block Serum Free: X0909, DakoCytomation, Glostrup, Denmark) for 20 min at room temperature. The cell culture slides were incubated with primary antibodies 1:500 dilution of mouse anti-H. pylori monoclonal primary antibody (Clone: BD1586; SC57780; Santacruz Biotechnology, Texas, Vt., USA) in TBS and rabbit anti-E-cadherin (24E10) polyclonal primary antibody (1:200 dilution in TBS) (3195; Cell Signaling, Massachusetts, Mass., USA) for $1 \mathrm{~h}$, washed, and then incubated with secondary antibodies 1:500 goat anti-mouse 
Alexa488 and 1:500 donkey anti-rabbit Alexa594 (Thermo Fisher Scientific, Inc., Waltham, MA, USA) for $1 \mathrm{~h}$. The cells were mounted with DAPI medium (ProLong Gold antifade reagent, Thermo Fisher Scientific, Inc., Waltham, MA, USA) and evaluated for evidence of $H$. pylori transmigration across the cell cleft at 40-100 $\times$ magnification under a confocal microscope. The multi-image layers were generated on the UltraVIEW VoX Spinning Disk confocal microscope from PerkinElmer using Volocity software while the 3D construction pictures were performed by confocal scanning microscope LSM800 from Carl Zeiss using Zen black software.

\subsection{Histopathology and E-cadherin Immunohistochemistry}

Liver tissue sections were deparaffinized and rehydrated before staining with hematoxylin and eosin (H\&E) (Sigma-Aldrich, Missouri, MO, USA). Histopathology such as periductal inflammation, goblet cell metaplasia, biliary dysplasia and mitotic figures were investigated.

E-cadherin expression was detected by immunohistochemistry similar to the immunofluorescence staining mentioned above. Briefly, liver sections were incubated with anti-E-cadherin monoclonal primary antibody (Clone: NCH-38; M3612; DakoCytomation, Glostrup, Denmark) at 1:50 dilution in TBS at $4{ }^{\circ} \mathrm{C}$ overnight. The slides were then incubated with biotinylated goat antibody mouse/rabbit immunoglobulin (K0675; DakoCytomation, Glostrup, Denmark) in TBS at 1:100 dilution for $1 \mathrm{~h}$. After three thorough washes, the slides were incubated in streptavidin-biotin-horseradish peroxidase (HRP) complex (Enzyme Label) (K0355; DakoCytomation, Glostrup, Denmark) solution for $1 \mathrm{~h}$. Unbound excess streptavidin complexes were removed through thorough washes and the slides were then developed in diaminobenzidine tetrahydrochloride solution for 5 min and rinsed in tap water. The liver sections were counterstained in Mayer's hematoxylin, dehydrated, cleared, mounted and observed under a light microscope. Positive biliary Ecadherin expression, as identified by brown staining, was quantified in the first and second order bile ducts in 10 non-overlapping fields of view at $20 \times$ high magnification (Olympus BX51, Olympus Coperation, Shinjuku-ku, Tokyo, Japan) using ImageJ software [20].

\subsection{Data Analysis}

All data were analyzed using SPSS version 23.0 (SPSS Inc., Chicago, IL, USA). The t-test was used to compare means between two groups and the analysis of variance (ANOVA) with post-hoc (LSD) was used to compare multiple groups. A $p$ value of $<0.05$ and $<0.01$ were considered as statistically significant.

\section{Results}

\subsection{Organ Distribution of H. pylori in Infected Hamsters}

To investigate the route of $H$. pylori migration to the bile duct, we first explored the H. pylori distribution in the relevant tissues. We used qPCR to quantify the expression of $H$. pylori-associated $g f p$ gene through copy number analysis of both transfected $H$. pylori strains in the stomach, blood, and bile fluid of each animal from all experimental groups, at one and three months after infection. In the O. viverrini co-infection group, the number of $H$. pylori in the worm was also examined. At 1 month post-infection, cagA-negative $H$. pylori was detected at significantly higher levels in the gastric mucosa of $O$. viverrini co-infected hamsters than in animals infected with cagA-positive, or cagA-negative or cagA-positive alone (Figure 2a). As expected, the $H$. pylori copy numbers of both strains in the stomach were significantly reduced at 3 month post-infection in all experimental groups. Both $H$. pylori strains were detected in the bile fluid and blood samples, regardless of $O$. viverrini co-infection. However, the copy numbers were significantly reduced 3-months post-infection (Figure $2 \mathrm{~b}-\mathrm{d}$ ). Interestingly, significantly higher cagA-positive $H$. pylori copy numbers were observed in the bile fluid samples at 3 months post-infection in the O. viverrini infection group, compared to animals co-infected with cagA-negative, or cagA-positive or cagA-negative $H$. pylori alone (Figure 2b). Both cagA-positive and cagA- 
negative $H$. pylori were found in the worms of the O. viverrini infection groups. However, the cagA-negative $H$. pylori copies were significantly decreased at 3 months compared to 1 month post-infection, whereas the cagA-positive counterparts showed slightly increased levels at 3 month post-infection (Figure 2d). No gfp-transfected H. pylori was found in any samples of $O$. viverrini infection alone (control) (Figure 2a-d). Detailed comparisons including the statistical analyses are described in the figure legends.

a

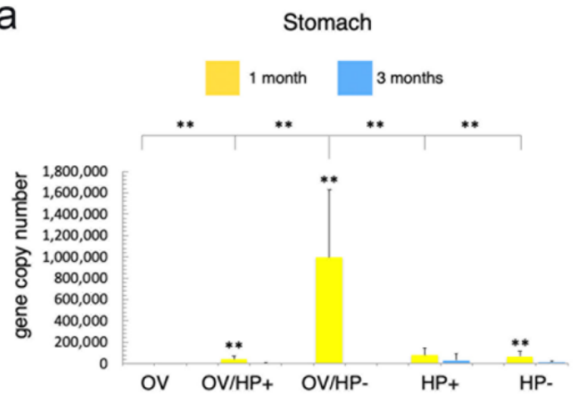

C

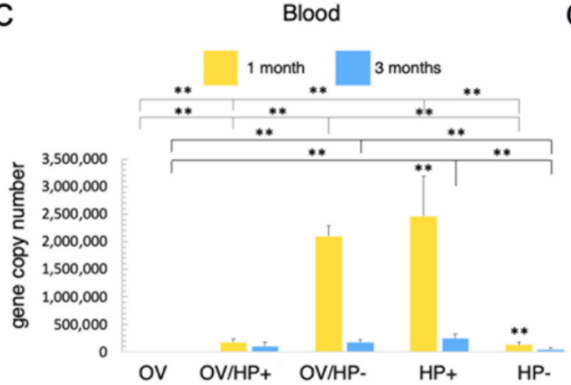

b

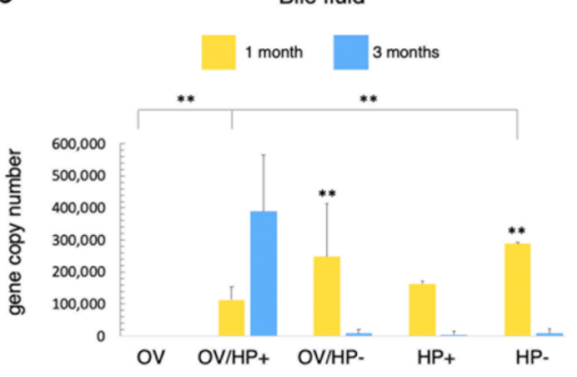

d

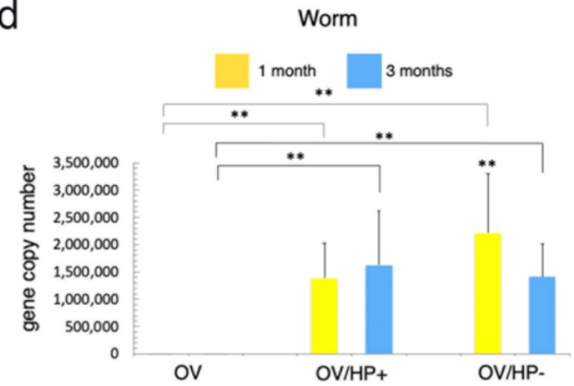

Figure 2. $g f p$ copy numbers representing the presence of H. pylori in the stomach (a), bile fluid (b), blood (c) and worms (d) from five different infection groups at 1- and 3-month post-infection. Statistical test using ANOVA, ${ }^{* *} p<0.01$. OV $=O$. viverrini infection alone, OV $/ \mathrm{HP}-=O$. viverrini infection + cagA-negative $H$. pylori, $\mathrm{OV} / \mathrm{HP}+=O$. viverrini infection + cagA-positive $H$. pylori, $\mathrm{HP}+=$ cag A-positive H. pylori infection alone, $\mathrm{HP}-=$ cagA-negative $H$. pylori infection alone.

\subsection{Route of Migration of H. pylori in O. viverrini Co-Infection}

The results from the distribution study led us to analyse the route of migration of cagA-positive $H$. pylori co-infection with $O$. viverrini for further investigation. The animals were co-infected with cagA-positive H. pylori and O. viverrini and examined for $g f p$ copies (representing H. pylori) in the stomach, blood, bile fluid, and worms at $3 \mathrm{~h}, 6 \mathrm{~h}, 1 \mathrm{month}$, and 3 months post-infection. H. pylori, as detected by gfp gene quantification, was observed at $3 \mathrm{~h}$ post-infection through to the end of experiments in all examined tissues, including the worms themselves (Figure 3a-d). The H. pylori levels in the stomach were gradually reduced from $3 \mathrm{~h}$ to 1 month and significantly decreased at 3 months post-infection (Figure $3 \mathrm{a}$ ), whereas those in the bile fluid and worms were significantly increased at 1 month and 3 months post-infection (Figure 3c,d). The H. pylori levels in the blood were gradually increased and reached their maximum at 1 month, before levels decreased again and were significantly reduced at 3 months post-infection compared to the first month (Figure $3 b$ ). Details of the statistical analyses are described in the figure legends. 
a

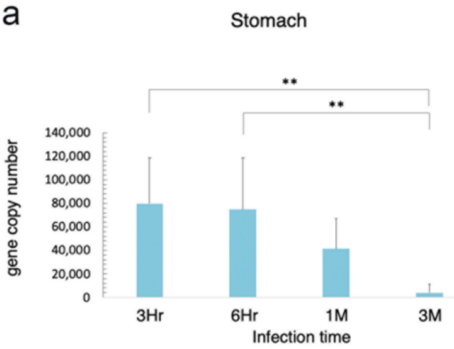

C

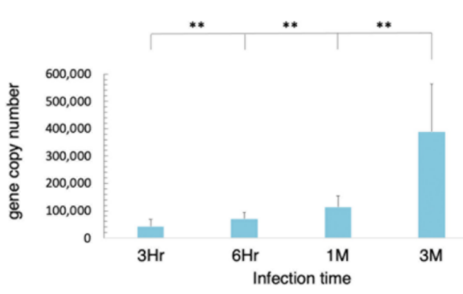

b

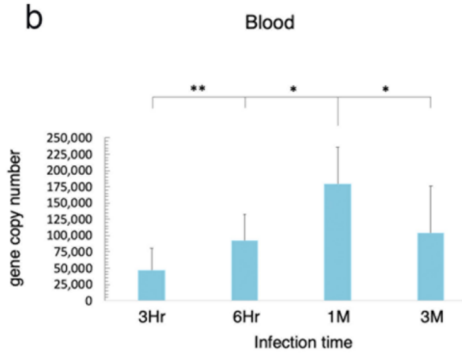

d

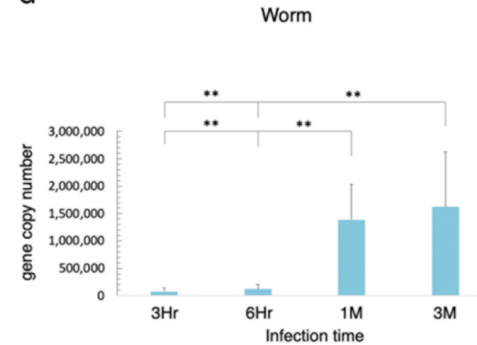

Figure 3. H. pylori copies based on $g f p$ detection in the stomach (a), blood (b), bile fluid (c) and worms (d) of O. viverrini co-infected with cagA-positive $H$. pylori at $3 \mathrm{~h}, 6 \mathrm{~h}, 1$ month and 3 months post-infection. Statistical test using ANOVA, ${ }^{*} p<0.05,{ }^{* *} p<0.01$. $\mathrm{Hr}=$ hour, $\mathrm{M}=$ month.

\subsection{O. viverrini Enhances H. pylori Colonization In Vivo}

Next, we investigated the effect of $O$. viverrini on $H$. pylori colonization in the bile ducts using a well-studied hamster model. Paraffin-embedded infected liver tissues were used to examine the presence of $H$. pylori. The number of H. pylori in the bile ducts and in the worms themselves were assessed semi-quantitatively by using immunofluorescent staining for green fluorescent protein (GFP). Both strains of $H$. pylori were observed at the biliary epithelial cell surface and perinuclear area in O. viverrini co-infected with $H$. pylori, but not in $\mathrm{H}$. pylori infection alone (Table 1 and Figure 4a-d). In addition, only cagA-positive H. pylori were also detected in the crypt of the large bile duct epithelium (Figure $4 \mathrm{~d}$ ). No H. pylori were detected in the small bile ducts. Both H. pylori strains were found on the tegument of the O. viverrini worms. However, only the cagA-positive strain was observed in the worm's gut (Table 1 and Figure $4 \mathrm{~b}$ ). The presence of GFP in H. pylori was confirmed by double immunofluorescence using antibodies to GFP and H. pylori (Figure 5).

Table 1. Detection of $H$. pylori in first order and second order bile ducts as well as worms using immunofluorescent staining. $+++=$ high numbers of $H$. pylori detection, $++=$ moderate numbers of $H$. pylori detection, $+=$ mild numbers of $H$. pylori detection. - = no H. pylori detection, NA = Not applicable

\begin{tabular}{|c|c|c|c|c|c|c|c|}
\hline \multirow{2}{*}{ Month. } & \multirow{2}{*}{ Groups } & \multicolumn{3}{|c|}{ 1st Order Bile Duct } & \multirow{2}{*}{$\begin{array}{l}\text { 2nd Order } \\
\text { Bile Duct }\end{array}$} & \multicolumn{2}{|c|}{ Worm } \\
\hline & & Surface & Peri-Nucleus & Crypt & & Tegument & Gut \\
\hline \multirow[t]{4}{*}{1} & $\mathrm{OV} / \mathrm{HP}+$ & ++ & + & $\begin{array}{c}20 \% \\
(1 / 5)\end{array}$ & - & + & + \\
\hline & $\mathrm{OV} / \mathrm{HP}-$ & +++ & + & $0 \%(0 / 5)$ & - & + & - \\
\hline & $\mathrm{HP}+$ & - & - & $0 \%(0 / 5)$ & - & NA & NA \\
\hline & $\mathrm{HP}-$ & - & - & $0 \%(0 / 5)$ & - & NA & NA \\
\hline \multirow[t]{4}{*}{3} & $\mathrm{OV} / \mathrm{HP}+$ & + & +++ & $\begin{array}{c}20 \% \\
(1 / 5)\end{array}$ & - & + & + \\
\hline & OV/HP- & + & +++ & $0 \%(0 / 5)$ & - & + & - \\
\hline & $\mathrm{HP}+$ & - & - & $0 \%(0 / 5)$ & - & NA & NA \\
\hline & HP- & - & - & $0 \%(0 / 5)$ & - & NA & NA \\
\hline
\end{tabular}


H. pylori (GFP)
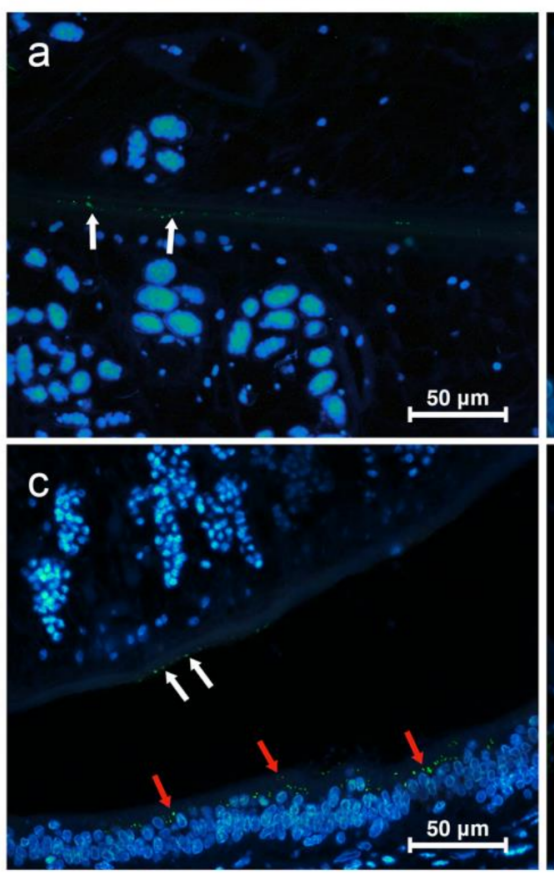

Hoechst
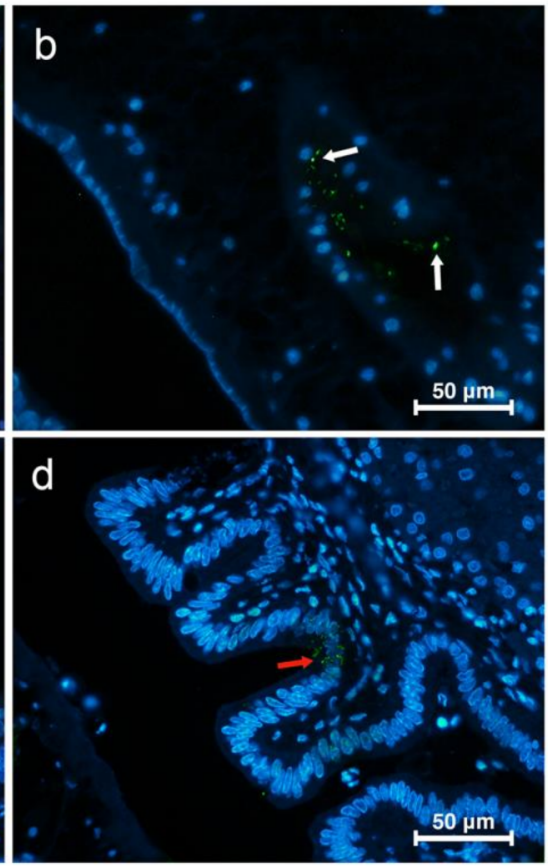

Figure 4. Representative pictures of H. pylori colonization. (a) H. pylori on the peri-tegumental surface of O. viverrini (white arrow); (b) H. pylori in the gut lumen and epithelium (White arrow); (c) H. pylori at the worm tegument (white arrow) and the 1st order bile duct epithelial cells (red arrow); (d) H. pylori in the epithelial crypt. The green channel represents GFP detected by Alexa488-labeled antibody. Blue channel represents cell nuclei by Hoechst staining. [a-d = Immunofluorescence, original magnification, $(\mathbf{a}-\mathbf{c}) \times 40$, (d) $\times 60$, scale bar depicts $50 \mu \mathrm{m}]$.
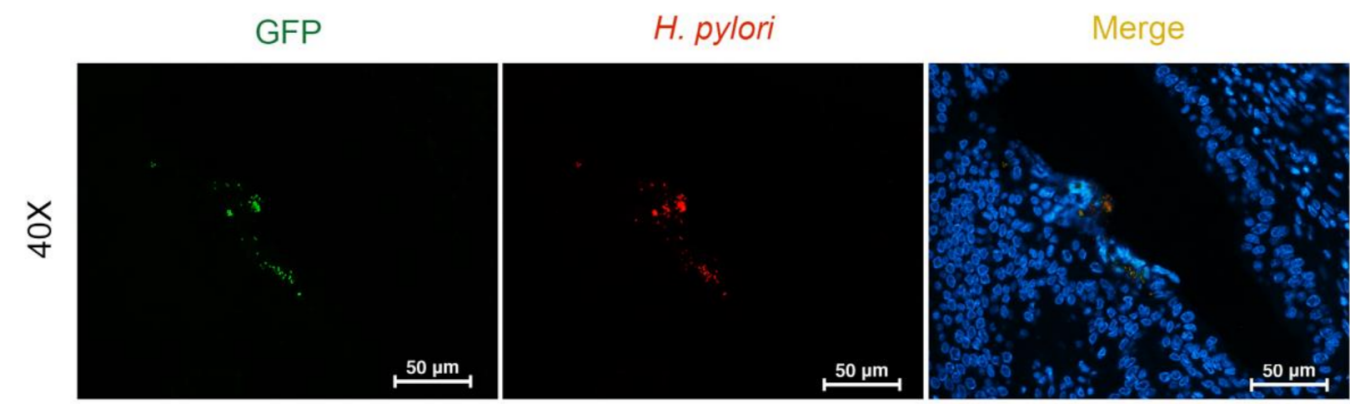

Figure 5. Co-expression of GFP and H. pylori in the biliary epithelium using immunofluorescent staining. The green channel represents GFP visualised with the Alexa488 antibody. The red channel represents $H$. pylori by the Alexa594 antibody. The blue channel represents nuclei by Hoechst staining. Merged yellow spots identifies the co-localization of both GFP and H. pylori (Immunofluorescence, original magnification, $\times 40$, scale bar depicts $50 \mu \mathrm{m})$.

\subsection{O. viverrini Excretory-Secretory Products Enhance H. pylori Binding to Bile Duct Epithelial} Cells In Vitro

To explore the effects of $O$. viverrini on $H$. pylori colonization, we performed an in vitro binding assay using the cholangiocyte cell line, H69 cocultured with cagA-positive H. pylori with or without $O$. viverrini excretory-secretory products. Fluorescent bacterial binding to $\mathrm{H} 69$ cells was assessed and counted per high power field (HP). The results showed that H. pylori adhered to the cell surface but was not detected in the cytoplasm (Figure 6a). Quantitatively, O. viverrini excretory-secretory products significantly enhanced the binding 
of H. pylori to the bile duct cell line $(27 \pm 6.5$ cells $/ \mathrm{HP})$ compared to those incubated with H. pylori alone $(13 \pm 3.8$ cells $/ \mathrm{HP})(p=0.023)$ (Figure $6 \mathrm{~b})$.

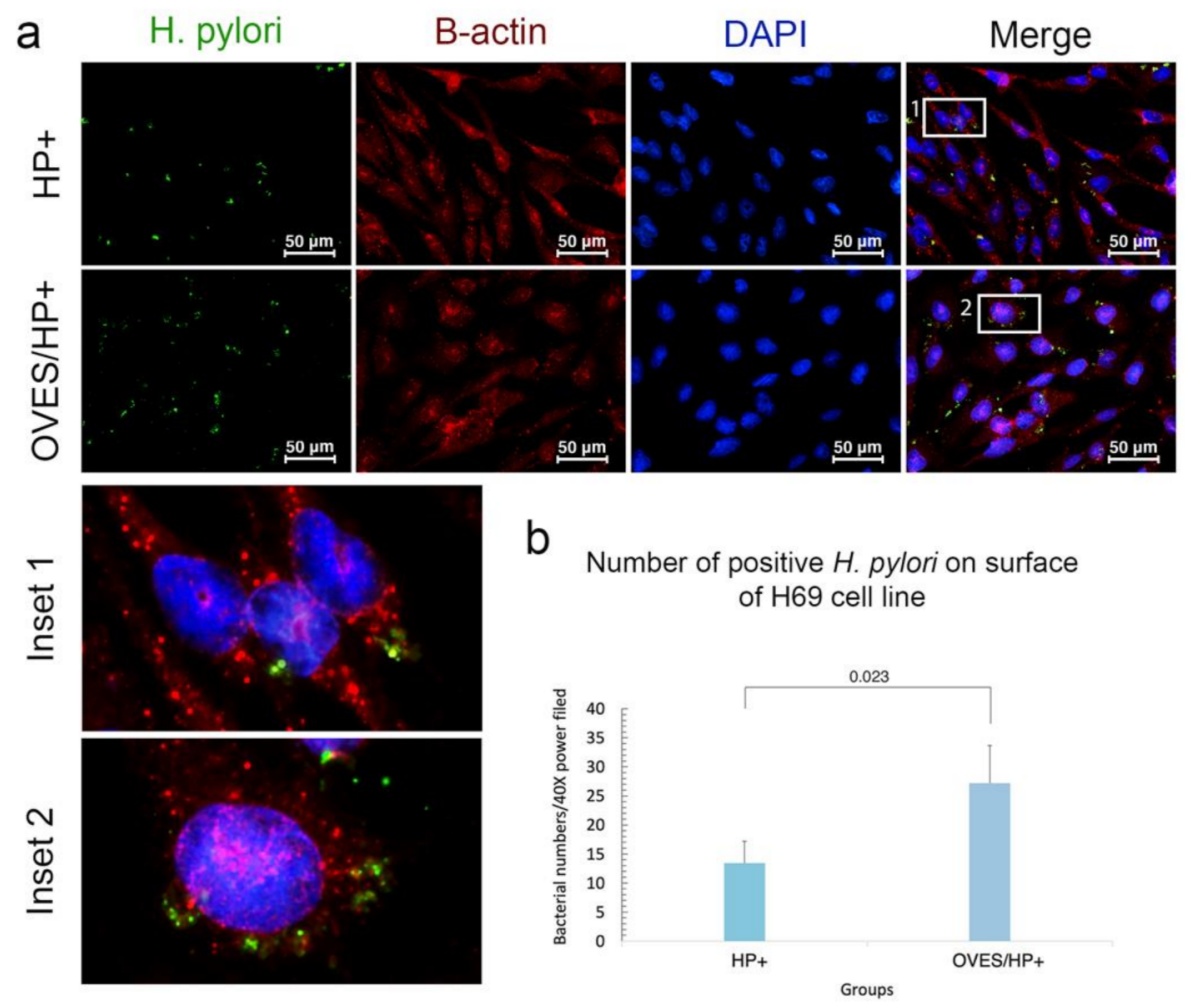

Figure 6. Adhesion assay of $H$. pylori to the biliary epithelial cell line. (a), representative pictures depict different amounts of $H$. pylori on the $\mathrm{H} 69$ cell surface, $\mathrm{HP}+=H$. pylori cag A+ bacteria alone, OVES $/ \mathrm{HP}+=$ excretory-secretory products + H. pylori cagA + bacteria. (b), significant bacterial number on $\mathrm{H} 69$ cells with excretory-secretory products than those without $(p=0.023)$. The green channel represents $H$. pylori by the Alexa488-labeled anti- $H$. pylori antibody. Red channel represents $\beta$-actin of $\mathrm{H} 69$ by the Alexa594-labeled anti- $\beta$-actin antibody. Blue channel represents the nuclei by DAPI staining [Immunofluorescence, original magnification, $\times 40$, scale bar depicts $50 \mu \mathrm{m}$ ].

\subsection{Effect of O. viverrini Excretory-Secretory Products on H. pylori Trans-Epithelial Migration} and E-Cadherin Expression In Vitro

To determine the effect of $O$. viverrini excretory-secretory products on $H$. pylori, transmigration, immunofluorescent staining and confocal microscopy were utilized to determine the location of H. pylori and the expression of E-cadherin in H69 biliary cells after 3, 6, and $24 \mathrm{~h}$ co-incubation with and without excretory-secretory products at 3 and $6 \mathrm{~h}$, the bacteria in excretory-secretory products co-incubated (OVES/ $\mathrm{HP}+)$ and $\mathrm{HP}+$ alone $(\mathrm{HP}+)$ were observed on the H69 apical surface, but not in the intercellular space. Interestingly, at $24 \mathrm{~h}$, H. pylori was detected at the basolateral surface in the OVES/HP+ biliary cells (Figure 7a) but not in cells incubated with $\mathrm{HP}+$ alone (Figure 7c). Three-dimensional reconstruction images confirmed the presence of $H$. pylori at the basolateral surface of the biliary cells co-incubated with excretory-secretory products (Figure 7b) but not $\mathrm{HP}+$ alone (Figure 7d). Concurrently, the level of E-cadherin expression was reduced in OVES/HP+ (Figure 7a) compared to those of $\mathrm{HP}+$ alone (Figure 7c). Control cells with no $\mathrm{HP}+$ and OVES showed normal E-cadherin expression with no H. pylori detection (Figure 7e). 
a

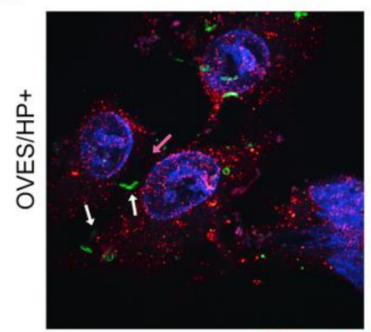

C

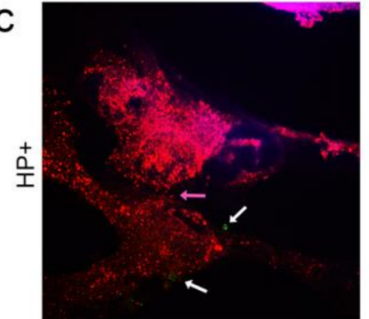

e

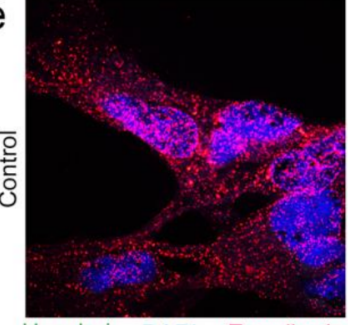

b
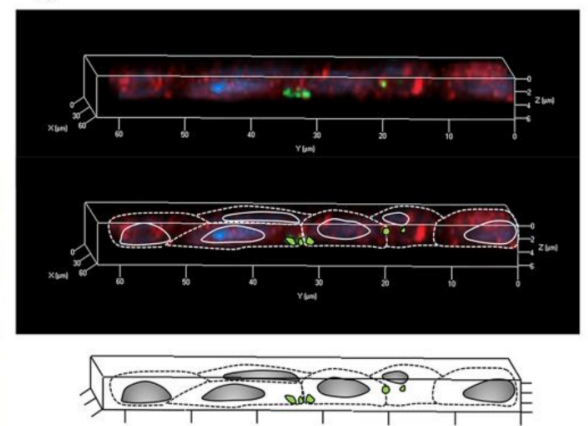

d
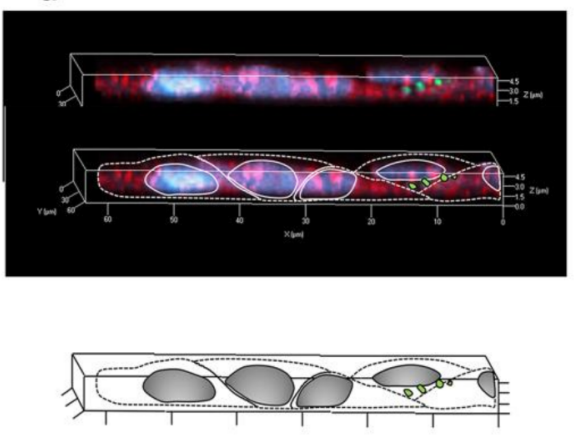

Figure 7. Confocal photomicrograph representing H. pylori on the epithelial gap. $(\mathbf{a}, \mathbf{b}) ; \mathrm{OVES} / \mathrm{HP}+=$ cell treated with excretory-secretory products + cagA-positive H. pylori. $(\mathbf{c}, \mathbf{d}) ; \mathrm{HP}+=$ cell treated with cagA-positive H. pylori. (a,c); the sectioned photomicrograph represents E-cadherin junction and transmigrated $H$. pylori. (the pink arrow points towards the epithelial gap, the white arrow identifies H. pylori) (b,d); 3D-reconstruction image of both co-incubation groups. The top picture is a 3Dreconstruction photomicrograph. The middle picture is a photomicrograph with an overlay of the diagram outlined below. (e); control $\mathrm{H} 69$ cells without OVES or $\mathrm{HP}+$ co-incubation. (Original magnification, $\times 100$, scale bar depicts $5 \mu \mathrm{m})$.

\subsection{Co-Infection of cagA-Positive H. pylori and O. viverrini Enhances Biliary Epithelial} Pathological Changes

Based on the hypothesis that $O$. viverrini facilitates $H$. pylori migration and colonization, we further investigated the potential enhancement role of $H$. pylori in the pathogenesis of opisthorchiasis and its associated CCA in a hamster model. Biliary changes including goblet cell metaplasia, biliary dysplasia and biliary proliferation were assessed by histopathology at 1- and 3-months post-infection. Overall, the epithelial changes were limited to the first order bile ducts the liver fluke inhabited (Figure $8 \mathrm{i}-\mathrm{ix}$ ). These included goblet cell metaplasia, biliary dysplasia, and proliferation. At 1-month post-infection, the lesions showed less severe pathological changes compared to the lesions from animals infected for 3 months. The pathological changes in the bile duct lesions were significantly progressed 3 months post-infection (Figure 8). O. viverrini infection induced goblet cell metaplasia (Figure 8i), biliary dysplasia (Figure 8ii) and proliferation (demonstrated by mitotic figures) (Figure 8iii) of the bile duct epithelia. Co-infection with cagA-positive H. pylori induced more severe goblet cell metaplasia, dysplasia, and cell proliferation (Figure 8iv,v,vi). No such enhancement was observed in cagA-negative $H$. pylori co-infected with $O$. viverrini hamsters (Figure 8vii,viii,ix). None of these pathological changes were seen in $H$. pylori infection alone (Figure $8 \mathrm{x}-\mathrm{xv}$ ). 


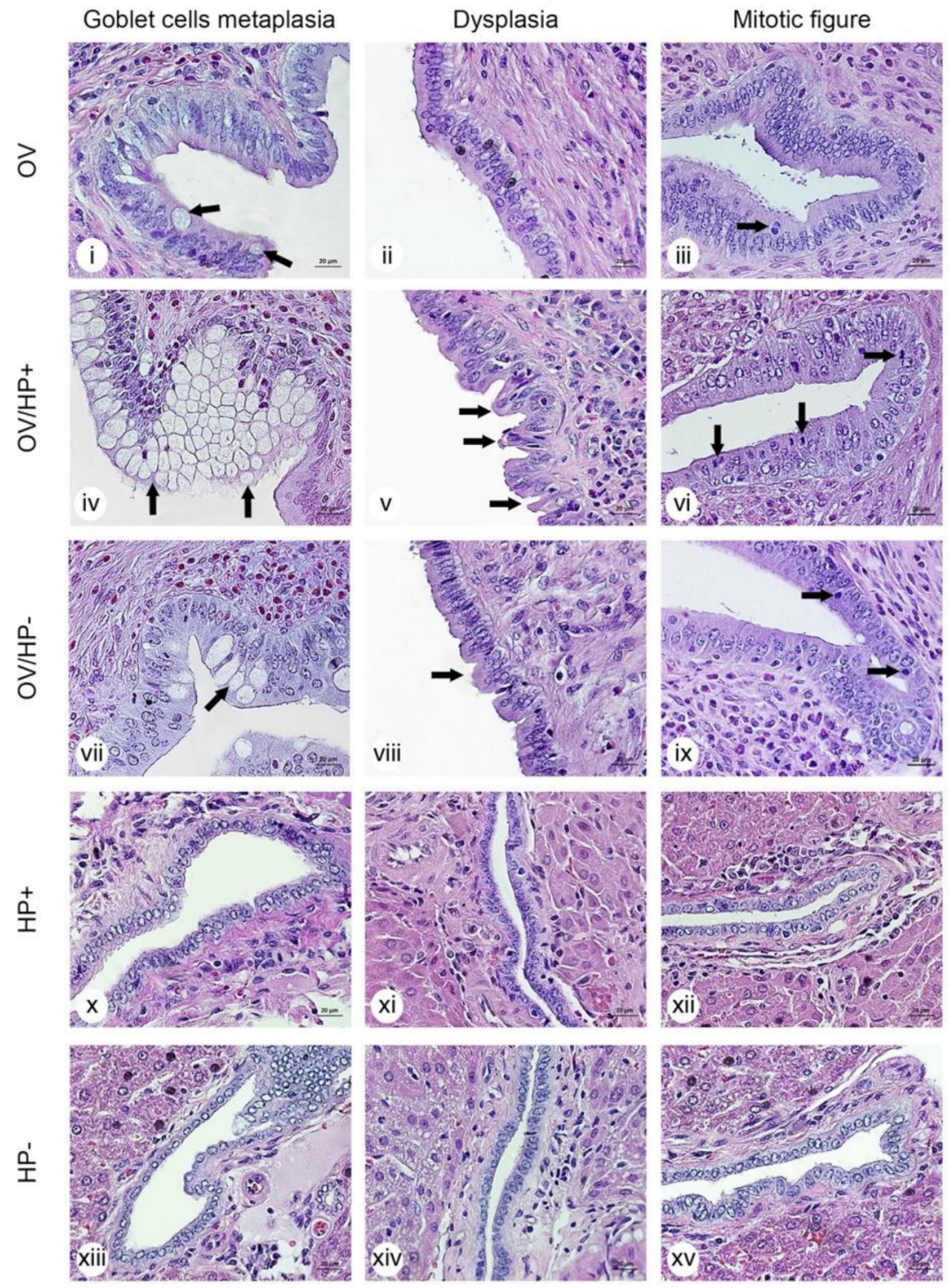

Figure 8. Representative micrographs of histopathological lesions at 3 months post-infection in 5-different experimental groups. $\mathrm{OV}=\mathrm{O}$. viverrini infection alone, $\mathrm{OV} / \mathrm{HP}-=O$. viverrini infection + cagA-negative $H$. pylori, $\mathrm{OV} / \mathrm{HP}+=$ O. viverrini infection + cagA-positive $H$. pylori, $\mathrm{HP}+=$ cagApositive $H$. pylori infection alone, $\mathrm{HP}-=$ cagA-negative $H$. pylori infection alone. Micrographs of goblet cell metaplasia in $\mathrm{OV}, \mathrm{OV} / \mathrm{HP}+, \mathrm{OV} / \mathrm{HP}-(\mathbf{i}, \mathbf{i v}$, vii) and no metaplasia development in $\mathrm{HP}+$, $\mathrm{HP}-(\mathbf{x}, \mathbf{x i i i})$, biliary dysplasia in $\mathrm{OV} / \mathrm{HP}+, \mathrm{OV} / \mathrm{HP}-(\mathbf{v}, \mathbf{v i i i})$ and no dysplasia development in $\mathrm{OV}$, $\mathrm{HP}+, \mathrm{HP}-(\mathbf{i i}, \mathbf{x i}, \mathbf{x i v})$, and proliferation (mitotic figures are identified with a black arrow) of OV, $\mathrm{OV} / \mathrm{HP}+, \mathrm{OV} / \mathrm{HP}-(\mathbf{i i i}, \mathbf{v i}, \mathbf{i x})$ and no proliferation in $\mathrm{HP}+, \mathrm{HP}-$, respectively (xii, xv). Micrographs in rows represent lesions in each treatment group. H\&E staining, original magnification, $\times 40$.

\subsection{Co-Infection of cagA Positive H. pylori and O. viverrini Reduces E-Cadherin Expression In Vivo}

Lastly, to assess the carcinogenic role of $H$. pylori/O. viverrini co-infection, expression of E-cadherin as a key cell adhesion molecule generally associated with malignant transformation-associated processes, was investigated in the biliary epithelium of infected hamsters. Qualitatively, intense cytoplasmic E-cadherin expression was observed in both the first and second order bile ducts of uninfected control hamsters. The expression of E-cadherin was quantitatively scored as mean intensity using ImageJ software. The results showed that E-cadherin expression levels in the bile duct epithelial cells was significantly lower in O. viverrini-infected groups $(\mathrm{OV}, \mathrm{OV} / \mathrm{HP}+, \mathrm{OV} / \mathrm{HP}-)$ compared to $H$. pylori-infected groups $(\mathrm{HP}+, \mathrm{HP}-)$ (Figure 9a-c). Importantly, co-infection of cagA-positive H. pylori and 
O. viverrini significantly reduced the E-cadherin expression (Figure $9 \mathrm{v}-\mathrm{viii})$. In contrast, cagA-negative $H$. pylori co-infected with $O$. viverrini had no effect on E-cadherin levels (Figure 9ix-xii), similar to data obtained with $H$. pylori infection alone (Figure 9xiii-xviii). Significant down-regulation of E-cadherin was found in both first and second order bile ducts of cagA-positive H. pylori co-infected with O. viverrini (Figure 9b,c).

a

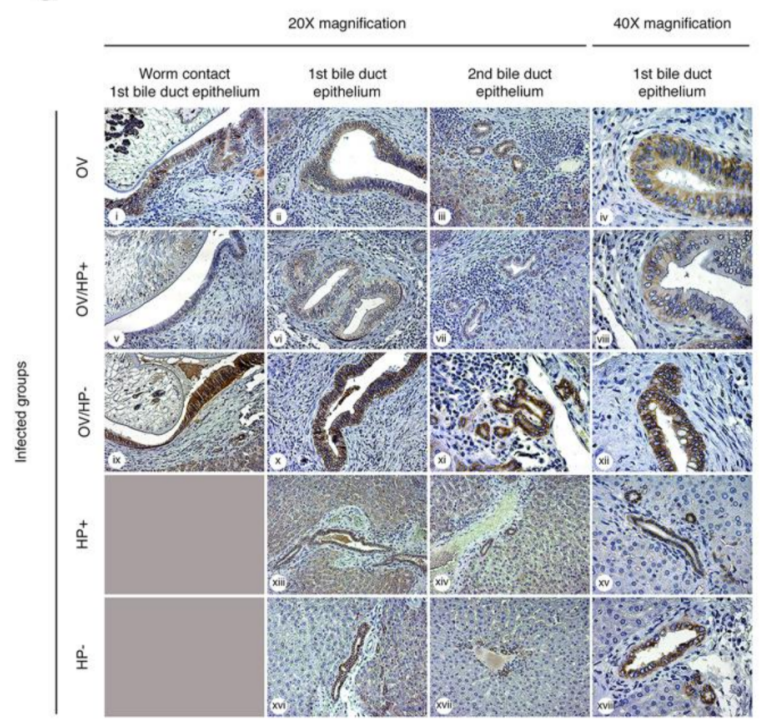

b

E-cadherin immunostaining the first order bile duct

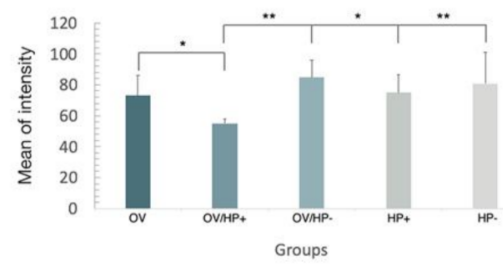

C

E-cadherin immunostaining the second order bile duct

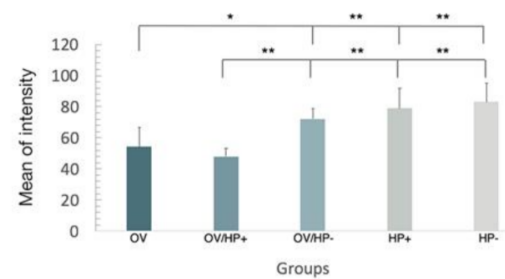

Figure 9. Immunohistochemical staining of E-cadherin in bile duct epithelia in each experimental group. (a) representative micrographs of E-cadherin staining in each group. Column 1, 2, and 4 represented the 1st order bile duct, Column 3 represented 2nd bile duct. The expression of E-cadherin was detected strongest colour in $\mathrm{OV} / \mathrm{HP}-(\mathbf{i x}-\mathbf{x i i}), \mathrm{HP}+(\mathbf{x i i i}-\mathbf{x v})$, and HP- (xvi-xviii). Moderate colour in $\mathrm{OV}(\mathbf{i}-\mathbf{i v})$, weakest colour in $\mathrm{OV} / \mathrm{HP}+(\mathbf{v}-\mathbf{v i i i})$. (b) the staining intensity was compared by means of positively stained biliary cell numbers in the first-order bile duct. (c) in the second-order bile duct. Significant differences are shown as ${ }^{*} p<0.05,{ }^{* *} p<0.01$. (Column $1-3=$ original magnification, $\times 20$; Column $4=$ original magnification, $\times 40$ ).

\section{Discussion}

Liver fluke infection caused by O. viverrini is a major public health problem in Southeast Asia and often results in diverse hepatobiliary pathologies including CCA [21]. Our group was the first to describe the association between CCA and H. pylori, particularly cagA-positive infection in liver fluke endemic areas in Thailand [10]. However, the mechanistic link between $O$. viverrini and $H$. pylori was unclear until recently. We discovered that $O$. viverrini is a reservoir of $H$. pylori [7] and co-infection of the two pathogens can enhance hepatobiliary abnormalities, specifically advanced periductal fibrosis in opisthorchiasis and cagA-positive H. pylori [9]. However, the mechanisms underlying enhanced carcinogenesis have remained elusive. Here, we showed that $O$. viverrini facilitated $H$. pylori migration, adhesion, and colonization, especially the cagA-positive strain. Moreover, co-infection also induced more severe biliary pathology, with down-regulated E-cadherin expression representing potentially malignant transformation. These results significantly contribute to our understanding of the underlying mechanisms and help to clarify how the liver fluke enhances cagA-positive $H$. pylori-induced severe opisthorchiasis and CCA.

H. pylori, a gram-negative bacterium, colonizes the gastric mucosa of humans and induces several gastrointestinal disorders, such as chronic gastritis, peptic ulcer, gastric cancer, and mucosa-associated lymphoid tissue lymphoma (MALT) [22,23]. In addition to the stomach, it has been found in the cardiovascular, nervous, pancreatic, and hepatobiliary systems $[24,25]$. However, the mechanisms by which $H$. pylori migrate to the extra-gastric tissues remain unclear. Two possible routes have been proposed for the migration to 
the hepatobiliary system: (1) ascending infection and (2) hematogenous spread [26-29]. In this study, we explored another possible route of $H$. pylori migration to the bile ducts when co-infected with the liver fluke, O. viverrini. We were able to detect $H$. pylori in the tegument and gut of the worms and in bile fluids, as early as three hours after infection, which is consistent with the time required for normal migration of $O$. viverrini to the bile ducts [12]. This suggests that H. pylori is "piggybacked" and co-migrates to the bile ducts via the juvenile worms. Detection of $H$. pylori in the blood also suggests the hematogenous migration route. However, where, and how H. pylori enter the blood circulation remains unknown. Ascending infection via bile duct obstruction is unlikely as no severe periductal fibrosis develops in this early stage. Nonetheless, enhancement of H. pylori migration into the biliary system may occur during chronic liver fluke infection.

Preference of cagA-positive H. pylori strain colonization in the biliary system in opisthorchiasis was evidenced in this study. By comparing the distribution of cagA-positive and cagA-negative $H$. pylori in the stomach, blood, bile fluid and adult worms of $O$. viverriniinfected hamsters, we demonstrated that the low virulence strain (cagA-negative) easily propagates at early infection (one month) but was significantly reduced at three months post-infection in all locations and worms studied. O. viverrini seems to enhance the colonization of the cagA-negative $H$. pylori at early stage of infection (one month). However, the mechanism of the rapid reduction of cagA-negative strain in chronic infection is unknown. Interestingly, in this study, the significantly higher number of cagA-positive compared to the cagA-negative $H$. pylori in the bile fluid and the adult worms at chronic stage (three months) implicates the establishment of the bacteria in the biliary system in $O$. viverrini infection. These findings support the significantly higher rates of cagA-positive $H$. pylori in opisthorchiasis compared to controls without O. viverrini infection in humans [9]. Moreover, the presence and specific hepatic genotypes of the H. pylori cagA gene are associated with the pathology of chronic opisthorchiasis, specifically periductal fibrosis [9]. The genetic differences of the gastric and enterohepatic Helicobacter species, reflecting mainly distinct metabolic functions, suggest the evolution and adaptation to different hosts, colonization niches, and mechanisms of virulence [30].

For colonization of $H$. pylori to the bile duct epithelium, we found that $H$. pylori was detected only in the $O$. viverrini co-infection groups. In addition, $H$. pylori colonization was observed only in the first-order bile ducts, where the liver fluke is found, but not in the secondary bile ducts, which are inaccessible to the worms. These results indicate that colonization of $H$. pylori to the bile duct epithelium is $O$. viverrini-dependent in this study. This conclusion is supported by our in vitro experiments, which showed that $O$. viverrini excretory-secretory products increased the binding of $H$. pylori on H69 biliary epithelial cells. Moreover, only cagA-positive $H$. pylori was found at the basolateral surface of the biliary cells. This indicates the pathogenetic significance of cagA in biliary pathology given that the cagA-positive, not the cagA-negative $H$. pylori strain is able to colonize the basolateral or intercellular spaces in gastric mucosa of gastritis patients [31]. However, the mechanisms underlying this enhanced colonization phenomenon are unknown. H. pylori employs multi-step processes to colonize the gastrointestinal mucosa, including the destruction of the mucous layer and binding to specific host receptors [32]. Several ligands and receptors for $H$. pylori binding have been identified; for example, BabA binds to Lewis $B$ antigens and $\mathrm{Le}^{\mathrm{b}}$ [33], SabA binding to sialyl-Le ${ }^{\mathrm{x}}$ [34], while LPS binding occurs to Toll-like receptor 4 (TLR4) $[35,36]$. To date, there is no conclusive evidence on how H. pylori colonizes the biliary system. Recently, we reported that a mucinase-like enzyme is one of the most abundant proteins detected in O. viverrini excretory-secretory products [37]. This O. viverrini mucinase-like enzyme may degrade or modify the mucous barrier on the bile duct epithelium and facilitate $H$. pylori adhesion and colonization. To establish colonization in the biliary system, $H$. pylori adhesins must bind to their specific receptors on the biliary epithelium. It is well-known that cholangiocytes express a variety of pathogenrecognition receptors including TLRs, particularly TLR4 [38] and MUC5AC, in health and diseases [39], which are the receptors for $H$. pylori $[40,41]$. Given that O. viverrini can induce 
overexpression of TLR4 [42] and MUC5AC [43], the liver fluke may enhance colonization through these host receptors.

Once H. pylori is colonized, it can activate cascades of signaling pathways leading to inflammatory cytokine release, cell proliferation, transformation, and malignancy [40,44]. Our study using an animal model now reports that $O$. viverrini and $H$. pylori co-infection enhances pathological and pre-neoplastic patterns, including goblet cell metaplasia, biliary hyperplasia, and dysplasia. Pre-cancerous lesions were detected at higher frequencies in the $O$. viverrini and cagA-positive $H$. pylori co-infection group than in any other group. In addition, hamsters that were co-infected with $O$. viverrini and cagA-positive $H$. pylori showed significantly reduced E-cadherin expression, especially in areas with dysplastic epithelium compared to $O$. viverrini infection alone or $O$. viverrini co-infected with cagA-negative H. pylori. The lower expression of E-cadherin in O. viverrini infection alone may be due to interleukin 6 (IL-6) and TGF- $\beta 1$ production during infection [42,45]. IL-6 and TGF- $\beta 1$ induced by excretory-secretory products reported in the human liver fluke, Clonorchis sinensis have been shown to down-regulate E-cadherin expression [46]. The more severe downregulation of E-cadherin expression in the biliary epithelium of $O$. viverrini co-infected with cagA-positive H. pylori signifies the enhancement effect of the bacteria. CagA of $H$. pylori can downregulate E-cadherin expression and is involved in epithelial differentiation and transformation leading to malignancy [47]. Reduced levels of E-cadherin are commonly found in dysplastic tissue and pre-cancerous lesions, such as oral cancer [48,49], gastric cancer [50], and gallbladder cancer [51]. In CCA, the reduction in E-cadherin expression is associated with cell transformation, tumor progression, invasion, and metastasis [52]. Overall, our results are in agreement with previous studies on the CagA virulence factor and the higher severity of H. pylori infection, gastritis, and gastric carcinogenesis [53-57].

In summary, this study is the first to demonstrate that the carcinogenic liver fluke, O. viverrine, facilitates migration and colonization of $H$. pylori in the bile ducts. In addition, we showed that $O$. viverrini preferentially allows the cagA-positive strain of $H$. pylori to colonize in the gut and the tegument. The results support the view that $O$. viverrini is a reservoir host of $H$. pylori, particularly the cagA-positive strain. In turn, the fluke may continuously release the bacteria into the bile fluid. This phenomenon allows these two carcinogenic pathogens to establish a chronic co-infection. Consequently, chronic co-infection further enhances carcinogenic phenotypic changes of the bile duct epithelium leading to bile duct malignancy. This study provides fundamental information for further investigations regarding molecular pathways on carcinogenesis of $H$. pylori and liver fluke co-infection-associated bile duct cancer.

Author Contributions: Conceptualization, B.S., S.T., J.E.E.T.-P. and S.S.; Methodology, W.S., J.E.E.T.-P., S.T., S.S.; Validation, B.S., S.T., and J.E.E.T.-P.; Formal Analysis, W.S., B.S., J.E.E.T.-P., S.T.; Investigation, W.S.; Resources, B.S., JTP; Writing - Original Draft Preparation, W.S., S.T.; Writing - Review \& Editing, B.S., J.E.E.T.-P.; Supervision, B.S., S.T., JTP; Funding Acquisition, B.S., J.E.E.T.-P. All authors have read and agreed to the published version of the manuscript.

Funding: This research was funded by the Royal Golden Jubilee Ph.D. Program (RGJ-PhD Program, grant \# PhD/0092/2557), the Thailand Research Fund (TRF) and Khon Kaen University. Partial supports were from the International Research Network (IRN) Program (IRN61W0004).

Institutional Review Board Statement: The study was conducted according to the guidelines of the Declaration of Helsinki, and approved by the Animal Ethics Committee of Khon Kaen University (AEKKU \#41/2561).

Data Availability Statement: Not applicable.

Acknowledgments: This study was supported by the Royal Golden Jubilee Ph.D. Program (RGJ-PhD Program, grant \# PhD/0092/2557), the Thailand Research Fund (TRF) and Khon Kaen University. Partial supports were from the International Research Network (IRN) Program (IRN61W0004). WS is an RGJ-PhD Scholar. BS is the TRF and Khon Kaen University (KKU) Senior Research Scholar. The authors would like to thank the Curtin Health Innovation Research Institute facility staff for technical 
assistance. We also acknowledge John T. Cathey for editing the manuscript via Publication Clinic KKU, Thailand.

Conflicts of Interest: The authors declare no conflict of interest.

\section{References}

1. Sithithaworn, P.; Andrews, R.H.; Van De, N.; Wongsaroj, T.; Sinuon, M.; Odermatt, P.; Nawa, Y.; Liang, S.; Brindley, P.J.; Sripa, B. The current status of opisthorchiasis and clonorchiasis in the Mekong Basin. Parasitol. Int. 2012, 61, 10-16. [CrossRef]

2. Sithithaworn, P.; Yongvanit, P.; Duenngai, K.; Kiatsopit, N.; Pairojkul, C. Roles of liver fluke infection as risk factor for cholangiocarcinoma. J. Hepatobiliary Pancreat. Sci. 2014, 21, 301-308. [CrossRef]

3. Sripa, B.; Brindley, P.J.; Mulvenna, J.; Laha, T.; Smout, M.J.; Mairiang, E.; Bethony, J.M.; Loukas, A. The tumorigenic liver fluke Opisthorchis viverrini-multiple pathways to cancer. Trends. Parasitol. 2013, 28, 395-407. [CrossRef] [PubMed]

4. IARC. Schistosomes, liver flukes and Helicobacter pylori. IARC Monogr. Eval. Carcinog. Risks Hum. 1994, 61, 1-241.

5. Sripa, B.; Deenonpoe, R.; Brindley, P.J. Co-infections with liver fluke and Helicobacter species: A paradigm change in pathogenesis of opisthorchiasis and cholangiocarcinoma? Parasitol. Int. 2017, 66, 383-389. [CrossRef] [PubMed]

6. $\quad$ Plieskatt, J.L.; Deenonpoe, R.; Mulvenna, J.P.; Krause, L.; Sripa, B.; Bethony, J.M.; Brindley, P.J. Infection with the carcinogenic liver fluke Opisthorchis viverrini modifies intestinal and biliary microbiome. FASEB J. 2013, 27, 4572-4584. [CrossRef]

7. Deenonpoe, R.; Chomvarin, C.; Pairojkul, C.; Loukas, A.; Brindley, P.J.; Sripa, B. The carcinogenic liver fluke Opisthorchis viverrini is a reservoir for species of Helicobacter. Asian. Pac. J. Cancer. Prev. 2015, 16, 1751-1758. [CrossRef] [PubMed]

8. Dangtakot, R.; Pinlaor, S.; Itthitaetrakool, U.; Chaidee, A.; Chomvarin, C.; Sangka, A.; Wilailuckana, C.; Pinlaor, P. Coinfection with Helicobacter pylori and Opisthorchis viverrini enhances the severity of hepatobiliary abnormalities in hamsters. Infect. Immun. 2017, 85, e00009-e00017. [CrossRef]

9. Deenonpoe, R.; Mairiang, E.; Mairiang, P.; Pairojkul, C.; Chamgramol, Y.; Rinaldi, G.; Loukas, A.; Brindley, P.J.; Sripa, B. Elevated prevalence of Helicobacter species and virulence factors in opisthorchiasis and associated hepatobiliary disease. Sci. Rep. 2017, 7, 1-11. [CrossRef]

10. Boonyanugomol, W.; Chomvarin, C.; Sripa, B.; Bhudhisawasdi, V.; Khuntikeo, N.; Hahnvajanawong, C.; Chumsuwan, A. Helicobacter pylori in Thai patients with cholangiocarcinoma and its association with biliary inflammation and proliferation. HРВ 2012, 14, 177-184. [CrossRef]

11. Bhamarapravati, N.; Thammavit, W.; Vajrasthira, S. Liver changes in hamsters infected with a liver fluke of man, Opisthorchis viverrini. Am. J. Trop. Med. Hyg. 1978, 27, 787-794. [CrossRef]

12. Kaewkes, S.; Sripa, B. Migratory pattern of Opisthorchis viverrini in hamsters. Southeast Asian. J. Trop. Med. 2004, 35, 306-308.

13. Heuermann, D.; Haas, R. A stable shuttle vector system for efficient genetic complementation of Helicobacter pylori strains by transformation and conjugation. Mol. Gen. Genet. 1998, 257, 519-528. [CrossRef]

14. Schmitt, W.; Odenbreit, S.; Heuermann, D.; Haas, R. Cloning of the Helicobacter pylori recA gene and functional characterization of its product. Mol. Gen. Genet. 1995, 248, 563-572. [CrossRef] [PubMed]

15. Tatematsu, M.; Yamamoto, M.; Shimizu, N.; Yoshikawa, A.; Fukami, H.; Kaminishi, M.; Oohara, T.; Sugiyama, A.; Ikeno, T. Induction of Glandular Stomach Cancers in Helicobacter pylori-sensitive Mongolian Gerbils Treated with N-Methyl-N-nitrosourea and N-Methyl-N"' ' -nitro-N-nitrosoguanidine in Drinking Water. Jpn. J. Cancer. Res. 1998, 89, 97-104. [CrossRef]

16. Hussain, I.; Tasneem, F.; Umer, M.; Pervaiz, A.; Raza, M.; Arshad, M.I.; Shahzad, N. Specific and Quantitative Detection of Human Polyomaviruses BKPyV and JCPyV in the Healthy Pakistani Population. Virol. J. 2017, 14, 86. [CrossRef] [PubMed]

17. Sambrook, J.; Russell, D.W. Purification of Nucleic Acids by Extraction With Phenol:chloroform. CSH Protoc. 2006, 2006, 4455. [CrossRef]

18. Whelan, J.A.; Russell, N.B.; Whelan, M.A. A method for the absolute quantification of cDNA using real-time PCR. J. Immunol. Methods 2003, 278, 261-269. [CrossRef]

19. Aida, Y.; Pabst, M.J. Removal of endotoxin from protein solutions by phase separation using Triton X-114. J. Immunol. Methods 1990, 132, 191-195. [CrossRef]

20. Schneider, C.A.; Rasband, W.S.; Eliceiri, K.W. NIH Image to ImageJ: 25 years of image analysis. Nat. Methods 2012, 9, 671-675. [CrossRef]

21. Sripa, B.; Tangkawattana, S.; Brindley, P.J. Update on Pathogenesis of Opisthorchiasis and Cholangiocarcinoma. Adv. Parasitol. 2018, 102, 97-113. [PubMed]

22. Peek, R.M.; Crabtree, J.E. Helicobacter infection and gastric neoplasia. J. Pathol. 2006, 208, 233-248. [CrossRef]

23. Ramirez, A.; Sánchez, R. Helicobacter pylori persistence: Biology and disease. Rev. Gastroenterol. Perú. 2008, 18, $258-266$.

24. Franceschi, F.; Gasbarrini, A.; Polyzos, S.A.; Kountouras, J. Extragastric diseases and Helicobacter pylori. Helicobacter 2015, 20, 40-46. [CrossRef] [PubMed]

25. Franceschi, F.; Zuccalà, G.; Roccarina, D.; Gasbarrini, A. Clinical effects of Helicobacter pylori outside the stomach. Nat. Rev. Gastroenterol. Hepatol. 2014, 11, 234-242. [CrossRef] [PubMed]

26. Huang, Y.A.N.; Fan, X.; Tang, Z.; Liu, L.I.; Tian, X.; Li, N. Detection of Helicobacter pylori DNA in peripheral blood from patients with peptic ulcer or gastritis. APMIS 2006, 114, 851-856. [CrossRef]

27. Kalia, N.; Bardhan, K.D. Of blood and guts: Association between Helicobacter pylori and the gastric microcirculation. J. Gastroenterol. Hepatol. 2003, 18, 1010-1017. [CrossRef]

28. Nath, G.; Gulati, A.K.; Shukla, V.K. Role of bacteria in carcinogenesis, with special reference to carcinoma of the gallbladder. World J. Gastroenterol. 2010, 16, 5395-5404. [CrossRef] 
29. Pellicano, R.; Ménard, A.; Rizzetto, M.; Mégraud, F. Helicobacter Species and Liver Diseases: Association or Causation? Lancet Infect. Dis. 2008, 8, 254-260. [CrossRef]

30. Mannion, A.; Shen, Z.; Fox, J.G. Comparative genomics analysis to differentiate metabolic and virulence gene potential in gastric versus enterohepatic Helicobacter species. BMC Genom. 2018, 19, 830. [CrossRef]

31. Camorlinga-Ponce, M.; Romo, C.; González-Valencia, G.; Muñoz, O.; Torres, J. Topographical localisation of cagA positive and cagA negative Helicobacter pylori strains in the gastric mucosa; an in situ hybridisation study. J. Clin. Pathol. 2004, 57, 822-828. [CrossRef] [PubMed]

32. Salama, N.R.; Hartung, M.L.; Müller, A. Life in the Human Stomach: Persistence Strategies of the Bacterial Pathogen Helicobacter pylori. Nat. Rev. Microbiol. 2013, 11, 385-399. [CrossRef]

33. Ilver, D.; Arnqvist, A.; Ögren, J.; Frick, I.M.; Kersulyte, D.; Incecik, E.T.; Berg, E.D.; Covacci, A.; Engstrand, L.; Borén, T. Helicobacter pylori adhesin binding fucosylated histo-blood group antigens revealed by retagging. Science 1998, 279, $373-377$. [CrossRef] [PubMed]

34. Mahdavi, J.; Sondén, B.; Hurtig, M.; Olfat, F.O.; Forsberg, L.; Roche, N.; Ångström, J.; Larsson, T.; Teneberg, S.; Karlsson, K.A.; et al. Helicobacter pylori SabA adhesin in persistent infection and chronic inflammation. Science 2002, 297, 573-578. [CrossRef] [PubMed]

35. Kao, C.Y.; Sheu, B.S.; Wu, J.J. Helicobacter pylori infection: An overview of bacterial virulence factors and pathogenesis. Biomed. J. 2016, 39, 4-23. [CrossRef] [PubMed]

36. Pachathundikandi, S.K.; Tegtmeyer, N.; Backert, S. Signal transduction of Helicobacter pylori during interaction with host cell protein receptors of epithelial and immune cells. Gut. Microbes 2013, 4, 454-474. [CrossRef]

37. Binh, T.T.T.; Nguyen, D.L.; Jala, I.; Dontumprai, R.; Plumworasawat, S.; Aighewi, O.; Ong, E.; Shawley, A.; Potriquet, J.; Saichua, P.; et al. Identification, recombinant protein production, and functional analysis of a M60-like metallopeptidase, secreted by the liver fluke Opisthorchis viverrini. Parasitol. Int. 2020, 75, 102050.

38. Chen, X.M.; O'Hara, S.P.; LaRusso, N.F. The Immunobiology of Cholangiocytes. Immunol. Cell Biol. 2008, 86, 497-505. [CrossRef]

39. Banales, J.M.; Huebert, R.C.; Karlsen, T.; Strazzabosco, M.; LaRusso, N.F.; Gores, G.J. Cholangiocyte pathobiology. Nat. Rev. Gastroenterol. Hepatol. 2019, 16, 269-281. [CrossRef] [PubMed]

40. Chmiela, M.; Kupcinskas, J. Review: Pathogenesis of Helicobacter pylori Infection. Helicobacter 2019, 24, e12638. [CrossRef]

41. Li, H.; Liao, T.; Debowski, A.W.; Tang, H.; Nilsson, H.O.; Stubbs, K.A.; Marshall, B.J.; Benghezal, M. Lipopolysaccharide Structure and Biosynthesis in Helicobacter pylori. Helicobacter 2016, 21, 445-461. [CrossRef]

42. Ninlawan, K.; O’Hara, S.P.; Splinter, P.L.; Yongvanit, P.; Kaewkes, S.; Surapaitoon, A.; LaRusso, N.F.; Sripa, B. Opisthorchis viverrini excretory/secretory products induce toll-like receptor 4 upregulation and production of interleukin 6 and 8 in cholangiocyte. Parasitol. Int. 2010, 59, 616-621. [CrossRef] [PubMed]

43. Sawanyawisuth, K.; Silsirivanit, A.; Kunlabut, K.; Tantapotinan, N.; Vaeteewoottacharn, K.; Wongkham, S. Novel Carbohydrate Antigen Expression During Development of Opisthorchis Viverrini-Associated Cholangiocarcinoma in Golden Hamster: A Potential Marker for Early Diagnosis. Parasitol. Int. 2012, 61, 151-154. [CrossRef] [PubMed]

44. Waskito, L.A.; Salama, N.R.; Yamaoka, Y. Pathogenesis of Helicobacter pylori Infection. Helicobacter 2018, 23, e12516. [CrossRef]

45. Jittimanee, J.; Sermswan, R.W.; Puapairoj, A.; Maleewong, W.; Wongratanacheewin, S. Cytokine Expression in Hamsters Experimentally Infected with Opisthorchis viverrini. Parasite Immunol. 2007, 29, 159-167. [CrossRef] [PubMed]

46. Won, J.; Cho, Y.; Lee, D.; Jeon, B.Y.; Ju, J.W.; Chung, S.; Pak, J.H. Clonorchis sinensis Excretory-Secretory Products Increase Malignant Characteristics of Cholangiocarcinoma Cells in Three-Dimensional Co-Culture with Biliary Ductal Plates. PLoS Pathog. 2019, 15, e1007818. [CrossRef] [PubMed]

47. Backert, S.; Tegtmeyer, N. Type IV Secretion and signal transduction of Helicobacter pylori CagA through interactions with host cell receptors. Toxins 2017, 9, 115. [CrossRef]

48. Kaur, J.; Sawhney, M.; DattaGupta, S.; Shukla, N.K.; Srivastava, A.; Walfish, P.G.; Ralhan, R. Clinical significance of altered expression of $\beta$-catenin and E-cadherin in oral dysplasia and cancer: Potential link with ALCAM expression. PLoS ONE 2013, 8, e67361. [CrossRef] [PubMed]

49. von Zeidler, S.V.; Souza Botelho, T.D.; Mendonça, E.F.; Batista, A.C. E-cadherin as a potential biomarker of malignant transformation in oral leukoplakia: A retrospective cohort study. BMC Cancer 2014, 17, 972. [CrossRef] [PubMed]

50. Zhou, D.; Guan, W.B.; Wang, J.D.; Zhang, Y.; Gong, W.; Quan, Z.W. A Comparative Study of clinicopathological features between chronic cholecystitis patients with and without Helicobacter pylori Infection in gallbladder mucosa. PLoS ONE 2013, 8, e70265. [CrossRef]

51. Choi, Y.L.; Xuan, Y.H.; Shin, Y.K.; Chae, S.W.; Kook, M.C.; Sung, P.H.; Youn, S.J.; Choi, J.W.; Kim, S.H. An immunohistochemical study of the expression of adhesion molecules in gallbladder lesions. J. Histochem. Cytochem. 2004, 52, 591-601. [CrossRef] [PubMed]

52. Techasen, A.; Loilome, W.; Namwat, N.; Khuntikeo, N.; Puapairoj, A.; Jearanaikoon, P.; Saya, H.; Yongvanit, P. Loss of E-cadherin Promotes Migration and Invasion of Cholangiocarcinoma Cells and Serves as a Potential Marker of Metastasis. Tumour Biol. 2014, 35, 8645-8652. [CrossRef] [PubMed]

53. Blaser, M.J.; Perez-Perez, G.I.; Kleanthous, H.; Cover, T.L.; Peek, R.M.; Chyou, P.H.; Stemmermann, G.N.; Nomura, A. Infection with Helicobacter pylori strains possessing cagA is associated with an increased risk of developing adenocarcinoma of the stomach. Cancer Res. 1995, 55, 2111-2115. 
54. Covacci, A.; Censini, S.; Bugnoli, M.; Petracca, R.; Burroni, D.; Macchia, G.; Massone, A.; Papini, E.; Xiang, Z.; Figura, N. Molecular characterization of the 128-kDa immunodominant antigen of Helicobacter pylori associated with cytotoxicity and duodenal ulcer. Proc. Natl. Acad. Sci. USA 1993, 90, 5791-5795. [CrossRef]

55. Crabtree, J.E.; Taylor, J.D.; Wyatt, J.I.; Heatley, R.V.; Shallcross, T.M.; Tompkins, D.S.; Rathbone, B.J. Mucosal IgA recognition of Helicobacter pylori $120 \mathrm{kda}$ protein, peptic ulceration, and gastric pathology. Lancet 1991, 338, 332-335. [CrossRef]

56. Gwack, J.; Shin, A.; Kim, C.S.; Ko, K.P.; Kim, Y.; Jun, J.K.; Bae, J.; Park, S.K.; Hong, Y.C.; Kang, D.; et al. CagA-producing Helicobacter pylori and increased risk of gastric cancer: A nested case-control study in Korea. Br. J. Cancer 2006, 95, 639-641. [CrossRef]

57. Valle, J.; Gisbert, J.P. Helicobacter pylori Infection and precancerous lesions of the stomach. Hepato-Gastroenterol. 2001, 48, 1548-1551. 